\title{
Theoretical and Numerical Study of Shear Strength of Concrete Material
}

\author{
Liu Jun ${ }^{1,2}$, Xiang Yuzhou ${ }^{3,4, *}$, Xiong Yucheng ${ }^{5}$, Wu zusong ${ }^{6,7}$ and He Chuan ${ }^{1}$ \\ ${ }^{1}$ School of Civil Engineering, Southwest Jiaotong University, Chengdu, Sichuan 610031, China \\ ${ }^{2}$ The 5th Engineering Co., Ltd of China Railway 11th Bureau Group, Chongqing 400037, China \\ ${ }^{3}$ Chongqing Chengtou Road and Bridge Administration Co., Ltd. Chongqing, 400023 \\ ${ }^{4}$ College of Civil Engineering, Chongqing University, Chongqing 400045, China \\ ${ }^{5}$ Enshi transportation planning and Design Company Limited Enshi, Hubei 445000 \\ ${ }^{6}$ International College, Chongqing Jiaotong University, Chongqing, 400074, China \\ ${ }^{7}$ Disaster sites, Kyushu University, Japan Research Center, Kyushu, Japan 819-0395
}

Received 14 May 2020; Accepted 27 September 2020

\begin{abstract}
The shear strength of some concrete materials should be analyzed based on elastic-plastic theory in petroleum, water conservancy, tunnel engineering, and so on. The majority of researches concentrate mainly on the tensile and compressive strength of concretes, but few have studied the shear strength. Concrete materials have been increasingly applied broadly to geotechnical engineering. Thus, investigating the shear strength characteristics of concretes is of great importance. To study the characteristics of shear strength of concrete materials, the theoretical relationship between concrete's compressive and shear strengths was discussed in the uniaxial, biaxial, and triaxial stress states. The concrete strength envelopes under the biaxial and uniaxial compressive strength were studied. Given the concrete shear strength, the overload method and the finite difference software FLAC3D were used to investigate the concrete failure modes and ultimate bearing capacities. Results show that the theoretical formula under the 3D stress-bearing condition is only applicable to the circumstance with equal compressive strengths under the biaxial and uniaxial conditions, which conforms to 3D Mohr's circle theory. 3D Mohr's circle theory is not totally applicable to concrete materials where the concrete compressive strength under the biaxial condition is larger than that under the uniaxial condition. Concrete material gains its shear strength 47 percent from its frictional force while the rest form cohesive force. The study results can provide a certain basis and reference for analyzing the shear strength characteristics of concrete materials.
\end{abstract}

Keywords: Overload method, Concrete, Shear strength, Compressive strength, Energy criterion

\section{Introduction}

Being the most widely used engineering material, concrete has been extensively applied to various fields, such as architecture, water conservancy, transportation, and national defense. Concrete has characteristics of tensile and compressive failure in architectural mechanics and tensile and shear failure in elastic-plastic mechanics. Some concrete materials are mainly under the elastic-plastic state in petroleum, water conservancy, geotechnical, and tunnel engineering applications [1-5]. For example, concrete is usually used to replace some rock and soil mass to improve the strength in geotechnical engineering. In this case, the analysis of concrete shear strength via the elastic-plastic mechanics research method is of great importance, but concrete shear strength has been rarely included in previous analyses.

According to the concept of elastic-plastic mechanics, concrete belongs to the rock and soil type friction material, which not only has cohesive force but also frictional force [6-9], and its shear strength is usually expressed approximately according to cohesion $c$ and internal friction angle $\varphi$. Nevertheless, concrete material is mostly expressed

\footnotetext{
"E-mail address: xyzcqu@126.com

ISSN: 1791-2377 @ 2020 School of Science, IHU. All rights reserved.

doi:10.25103/jestr. 135.21
}

by the compressive strength in architectural mechanics, not by the shear strength. The main differences between architectural and elastic-plastic mechanics lie in their development sequence, processing of mechanical methods, and material strength index, but they are essentially the same. With the increasing extensive applications of concrete materials in rock and soil mass engineering, the two computing methods must be combined to be applicable to both traditional architectural and classical elastic-plastic mechanics.

On this basis, the theoretical relationships between concrete's compressive and shear strength under the uniaxial, biaxial, and triaxial stress states were discussed and derived. The overload method and the finite difference software FLAC3D were adopted to study the concrete failure modes and the ultimate bearing capacities (compressive strength) to provide a new idea for studying the shear strength characteristics of concrete materials.

\section{State of the art}

Concrete materials have been extensively applied in fields, such as architecture and water conservancy, and scholars have conducted research on concrete materials as early as in the 1940s. Yu et al. [10] studied the mechanical properties of plain concrete (standard compressive strength was $30 \mathrm{MPa}$ ) under different axial compressions and then obtained the 
Liu Jun, Xiang Yuzhou, Xiong Yucheng, Wu zusong and He Chuan/

\section{Journal of Engineering Science and Technology Review 13 (5) (2020)161 - 168}

concrete shear failure mode and the shear load-displacement curves. Their results show that concrete shear failure behaviors vary with the axial compression to a great extent, and the shear bearing capacity of concrete increases with the axial compression ratio, but the influence of the triaxial stress state on concrete shear failure behaviors was not investigated. French et al. [11] explored the mechanical properties of concrete under uniaxial compression through a test and described the evolution of the direct shear behaviors of concrete specimens under static and dynamic loads based on the time and frequency-domain data. Cong [12] proposed a new method that integrates the straight shear and uniaxial compression tests, but is lacking mechanical analysis under the triaxial stress state and systematic tendency verification through the numerical calculation method. Rukhaiyar et al. [13] studied the concrete mechanical properties under triaxial stress, and their results reveal that the strength prediction error for ordinary concrete is the minimum under the Hsieh-Ting-Chen criterion and small based on the Drucker-Prager criterion for high-strength concrete. Javanmardi [14] conducted uniaxial and triaxial tests on cylindrical confined concrete specimens and calculated the relationships among the axial stress, the lateral confining stress, and the uniaxial compressive strength. These tests could help analyze the concrete strength laws from the perspective of triaxial stress conditions very well, thus providing a certain reference for subsequent studies. Yang et al. [15] researched the mechanical properties of hightemperature and strength fiber reinforced concretes and analyzed the effects of the content of recycled coarse aggregate on the shear strength, peak shear strain, stressstrain curve, and shear modulus of the specimens. These studies analyzed the mechanical characteristics of concrete materials from the perspectives of temperature and material characteristics and extended the research scope of the mechanical properties of concrete material, like shear. Ahmed [16] performed 27 direct shear push-off tests on high-strength concrete with and without steel fiber reinforcement, proposed the calculation formula of direct shear strength, and verified the test results with those of other series. Wang [17] studied the failure mechanism of ultrashort steel fiber reinforced concrete under compression and shear composite loading conditions, discussed further the relationship between the strength index and the fiber volume fraction, and drew conclusions that could provide a reference for engineering design and material selection, however, the shear strength theory of the concrete was not researched intensively. Deng [18] explored the shear performance difference between recycled and common concretes under the equal strength condition. The study indicated that the stress-strain curve of the recycled concrete is similar to that of common concrete, and its shear modulus increases with the shear strength. Arezoumandi [19] conducted an experimental investigation of the shear performance of fly ash concrete with a large adulterate amount and common concrete. Lim [20] performed a finite element simulation to study the mechanical behaviors of concrete under uniaxial, biaxial, and triaxial compressions, proposed and popularized the application of the Lubliner plastic model of concrete damage under uniaxial, biaxial, and triaxial compressions, and verified the shear characteristics of concrete from the numerical perspective very well. However, the occurrence mechanism of this phenomenon was not analyzed further.

Given the limitations of the existing researches, concrete strength was included to establish the theoretical relationship between the compressive and shear strength, which was verified through the numerical ultimate analysis method and is expected to provide more theoretical bases and mechanical characteristic laws for investigating concrete shear strength.

The structure of this study is organized as follows. Section 3 discusses the theoretical relationship among concrete shear stress, normal stress, and shear strength and mainly derives the three-shear energy criterion of the friction-type material and the variable-strength energy criterion of the concrete on offset plan. Section 4 presents the numerical simulation of the compressive and shear strengths of the concrete specimens and verifies the concrete shear strength based on theoretical calculation and numerical analysis. Section 5 summarizes this study and provides relevant conclusions.

\section{Methodology}

3.1 Theoretical relationship derivation of concrete shear stress, normal stress and shear strength

\subsubsection{Derivation of three-shear energy criterion of friction-type material}

Mechanical relationships certainly exist among concrete shear stress, normal stress, and shear strength. Theoretical analysis indicates that friction-type material follows the Mohr-Coulomb criterion in the biaxial stress state (intermediate principal stress not considered). On the basis of the traditional 3D Mohr's stress circle theory, 3D Mohr's circle theory is not totally applicable to concrete material in the 3D stress state. Based on 3D Mohr's stress circle theory (intermediate principal stress considered) complies with three-shear energy criterion proposed by Gao-Zheng Formulas (1), (2), and (3) express the three-shear energy yield criteria, taking tensile stress as a positive stress.

$$
\begin{aligned}
& p \sin \varphi+\frac{q}{3}\left(\sqrt{3} \cos \theta_{\sigma}-\sin \theta_{\sigma} \sin \varphi\right) \\
& =2 c \cos \varphi \sqrt{\frac{1-\sqrt{3} \tan \theta_{\sigma} \sin \varphi}{3+3 \tan ^{2} \theta_{\sigma}-4 \sqrt{3} \tan \theta_{\sigma} \sin \varphi}}
\end{aligned}
$$

or

$$
\begin{aligned}
& \frac{\sigma_{1}-\sigma_{3}}{2}+\frac{\sigma_{1}+\sigma_{3}}{2} \sin \varphi \\
& =c \cos \varphi \sqrt{\frac{1-(2 \beta-1) \sin \varphi}{\beta^{2}-\beta+1+\sin \varphi(1-2 \beta)}} \\
& \partial \beta=\frac{\sigma_{2}-\sigma_{3}}{\sigma_{1}-\sigma_{3}}
\end{aligned}
$$

The above formulas can be degraded into the Mises criterion for metal materials and the Mohr-Coulomb criterion for geotechnical materials under the single-shear circumstance.

As a general rule, geotechnical materials take compressive stress as positive stress, and relevant formula with compressive stress taken as positive stress is provided. The three-shear energy criterion is presented as follows: 


$$
\begin{aligned}
& -p \sin \varphi+\frac{q}{3}\left(\sqrt{3} \cos \theta_{\sigma}-\sin \theta_{\sigma} \sin \varphi\right) q \\
& =2 c \cos \varphi \sqrt{\frac{1-\sqrt{3} \tan \theta_{\sigma} \sin \varphi}{3+3 \tan ^{2} \theta_{\sigma}-4 \sqrt{3} \tan \theta_{\sigma} \sin \varphi}}
\end{aligned}
$$

or

$$
\begin{aligned}
& \frac{\sigma_{1}-\sigma_{3}}{2}+\frac{\sigma_{1}+\sigma_{3}}{2} \sin \phi \\
& =c \cos \phi \sqrt{\frac{1-(2 \beta-1) \sin \phi}{\beta^{2}-\beta+1+\sin \phi(1-2 \beta)}} \\
& \beta=\frac{\sigma_{1}-\sigma_{2}}{\sigma_{1}-\sigma_{3}} .
\end{aligned}
$$

When $\theta= \pm 30^{\circ}$, Formula (1),

$$
2 \sqrt{\frac{1-\sqrt{3} \tan \theta_{\sigma} \sin \varphi}{3+3 \tan ^{2} \theta_{\sigma}-4 \sqrt{3} \tan \theta_{\sigma} \sin \varphi}}=1 .
$$

In Formula (6),

$$
\sqrt{\frac{1-(2 \beta-1) \sin \varphi}{\beta^{2}-\beta+1+\sin \varphi(1-2 \beta)}}=1
$$

The Mohr-Coulomb criterion is expressed as follows:

$$
-p \sin \varphi+\frac{q}{3}\left(\sqrt{3} \cos \theta_{\sigma}-\sin \theta_{\sigma} \sin \varphi\right) q=c \cos \varphi
$$

or

$\frac{\sigma_{1}-\sigma_{3}}{2}-\frac{\sigma_{1}+\sigma_{3}}{2} \sin \varphi=c \cos \varphi$

The concrete specimen satisfies $\theta_{3}=0$ under the biaxial stress state and at time

$$
\sigma_{1}=\frac{2 c \cos \varphi}{(1-\sin \varphi)} \sqrt{\frac{1-(2 \beta-1) \sin \varphi}{\beta^{2}-\beta+1+\sin \varphi(1-2 \beta)}} .
$$

Without considering the intermediate principal stress, it can be written into the following forms according to the Mohr-Coulomb formula:

$$
\begin{aligned}
& \sigma_{1}=\frac{1+\sin \varphi}{1-\sin \varphi} \sigma_{3}+\frac{\cos \varphi}{1-\sin \varphi} 2 c, \\
& \tau=c+\sigma \tan \varphi=\frac{\sigma_{1}-\sigma_{3}}{2} \cos \varphi, \\
& \sigma=\frac{\sigma_{1}+\sigma_{3}}{2}-\frac{\sigma_{1}-\sigma_{3}}{2} \sin \varphi, \\
& c=\left[\frac{\sigma_{1}-\sigma_{3}}{2}-\frac{\sigma_{1}+\sigma_{3}}{2} \sin \varphi\right] \frac{1}{\cos \varphi},
\end{aligned}
$$

where $\tau$ and $\sigma$ are the shear and normal stresses on the shear failure plane, respectively.

$\sigma_{2}=\sigma_{3}=0$ holds when the concrete specimen is at the unidirectional stress state and can be simplified into the following forms:

$\sigma_{1}=\frac{\cos \varphi}{1-\sin \varphi} 2 c$,

$\tau=\frac{\sigma_{1}}{2} \cos \varphi$

$\sigma=\frac{\sigma_{1}}{2}(1-\sin \varphi)=c \cos \varphi$

Fig. 1 presents the limit curves of the Mohr-Coulomb criterion and the three-shear energy criterion of the C25 concrete specimen in the principal stress space. The calculation is implemented via the FLAC3D software, and the calculation parameters are provided in Tab. 2. With tensile stress taken as positive stress, $\sigma_{3}$ is the maximum compressive stress. Considering the calculation accuracy, four decimal places are taken for the value of cohesion $c$. The figure also displays the concrete strength limiting curves obtained by Kupfer based on a test in the bidirectional stress state. Under the five bidirectional compression test loading schemes of the concrete specimens, namely, the loading stress ratios $\sigma_{3} / \sigma_{2}$ (tensile stress is taken as positive stress, $\sigma_{3}$ is namely $\sigma_{1}$ ) of $-1 / 0,-1 /-1,-1 /-0.25,-1 /-0.50$, and $-1 /-$ 0.52 , the finite element calculation results of the MohrCoulomb criterion are compared with those of the threeshear energy criterion first, which are consistent with each other under the unidirectional stress state $\left(\sigma_{3} / \sigma_{2}=-1 / 0\right)$ and have a high goodness of fit under the equal-proportional compressive stress state $\left(\sigma_{3} / \sigma_{2}=-1 /-1\right)$. Under the stress ratio of $\sigma_{3} / \sigma_{2}=-1 /-0.25$, the maximum compressive strength obtained through the Mohr-Coulomb criterion is lower than that through the three-shear energy criterion by $23 \%$. The compressive strength obtained through the finite element calculation based on the Mohr-Coulomb criterion is compared with that according to the strength envelope of the Kupfer test, and the results are consistent with each other under the unidirectional stress state $\left(\sigma_{3} / \sigma_{2}=-1 / 0\right)$. Under the equal-proportional stress state $\left(\sigma_{3} / \sigma_{2}=-1 /-1\right)$, the finite element calculation result is lower than the fitted value in the test by $16 \%$. When the stress ratio is $\sigma_{3} / \sigma_{2}=-1 /-0.25$, the finite element calculation result is lower than the fitted value by $25 \%$. Tab. 1 lists the compressive strength ratios obtained through calculation based on the two criteria above and those obtained through the strength limiting curve according to the Kupfer test.

The above table shows that for concrete material, the limiting curves of both the Mohr-Coulomb and three-shear energy criteria have certain gaps from the test limiting curve in the bidirectional stress state. Comparatively, the MohrCoulomb limiting curve is partially conservative and can serve as a strength criterion for concrete. Through the strength envelope of the Kupfer test, the traditional 3D Mohr's circle theory in mechanics is not completely applicable to concrete material. According to 3D Mohr's stress circle theory, the concrete compressive strengths 
Liu Jun, Xiang Yuzhou, Xiong Yucheng, Wu zusong and He Chuan/

Journal of Engineering Science and Technology Review 13 (5) (2020)161 - 168

under the bidirectional isobaric and unidirectional stress conditions are equal (i.e., $\sigma_{c}$ ), so Formulas (1) and (2) are called the constant-strength three-shear energy criteria. However, the test indicates that the concrete compressive strengths under the two stress states are unequal, and the compressive strength $\left(\sigma_{c c}\right)$ under the bidirectional isobaric condition is larger than that $\left(\sigma_{c}\right)$ in the unidirectional stress state. Therefore, compressive strength $\sigma_{2}$ and the threeparameter strength criterion under the bidirectional isobaric condition are introduced in concrete mechanics. Theoretical analysis indicates that $\sigma_{c c}$ is related to the intermediate principal stress. The calculation indicates that $\sigma_{c c}$ increases correspondingly with the reduction of $\sigma_{2}$ in Formula (2). Thus, $\sigma_{2}$ reduction coefficient $k$ is introduced into Formula

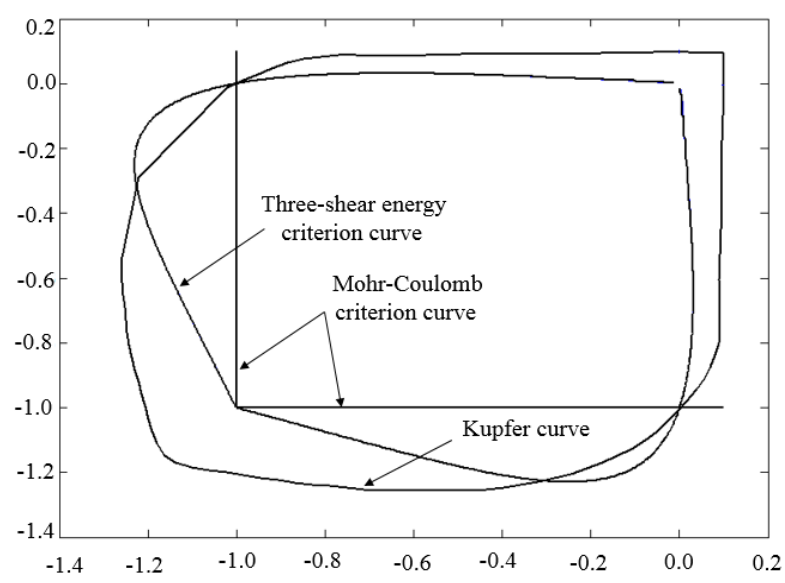
(3).

Fig. 1. The concrete strength envelopes under biaxial stress

Table 1. The concrete compressive strength under biaxial

\begin{tabular}{c|c|c|c|c}
\hline $\begin{array}{c}\text { Stress ratio } \\
/ \sigma_{3} / \sigma_{2}\end{array}$ & $\begin{array}{c}\text { Mohr-Coulomb } \\
\text { compressive strength } \\
/ \sigma_{\text {mohr }} /\left|\sigma_{c}^{\prime}\right|\end{array}$ & $\begin{array}{c}\text { Three-shear energy } \\
\text { compressive strength } \\
/ \sigma_{t} /\left|\sigma_{c}^{\prime}\right|\end{array}$ & $\begin{array}{c}\text { Kupfer compressive strength } \\
/ \sigma_{\text {Kuffer }} /\left|\sigma_{c}^{\prime}\right|\end{array}$ & $\begin{array}{c}\text { Bidirectional isobaric three-shear energy } \\
\text { compressive strength } \\
/ \sigma_{t} /\left|\sigma_{c}^{\prime}\right|\end{array}$ \\
\hline$-1 / 0$ & 1 & 1 & 1 & 1 \\
$-1 /-1$ & 1 & 1 & 1.16 & 1.16 \\
$-1 /-0.25$ & 1 & $1.23(\max )$ & 1.20 & $1.23(\max )$ \\
$-1 /-0.40$ & 1 & 1.14 & $1.25(\max )$ & $1.23(\max )$ \\
$-1 /-0.52$ & 1 & & \\
\hline
\end{tabular}

$$
\beta=\frac{k \sigma_{2}-\sigma_{3}}{\sigma_{1}-\sigma_{3}} \quad 0.25 \leq k \leq 1
$$

When $k=0.25,0.50,0.75,1.00$, the corresponding strength envelopes are shown in Fig. 2. According to Fig. 2, the strength envelopes intersects with $\sigma_{2}=\sigma_{3}$, and the corresponding $\sigma_{c c}$ values are $1.24 \sigma_{c}, 1.16 \sigma_{c}, 1.08 \sigma_{c}$, and $\sigma_{c}$, respectively. Under the $k=1$ condition, if $\sigma_{c c}=\sigma_{c}$, then the strength envelope is the three-shear energy strength envelope, that is, the concrete strength envelope in the equal strength circumstance. When $k=0.5$, the corresponding three-shear energy strength envelope is very approximate to the strength envelope of the Kupfer test. Formula (2) can serve as the concrete strength criterion. At this time, $\sigma_{c c} \neq \sigma_{c}$, that is, the concrete strength envelope under the variable-strength conditions as shown in Fig. 3. When $k=$ 0.504, $\sigma_{c c}$ on the fitted curve overlaps with $\sigma_{c c}$ on the strength envelope of the Kupfer test. Then, $\sigma_{c c}=1.154$.

As the points of intersection are on the same straight line, the following can be obtained according to the proportional relation: $\sigma_{c c}=-0.32 k \sigma_{c}+1.32 \sigma_{c}$

$\sigma_{c c}=-0.32 k \sigma_{c}+1.32 \sigma_{c}$,

$k=\frac{1.32-\sigma_{c c} / \sigma_{c}}{0.32}$.

According to the calculation, when $k$ is applicable to the ( $1 \geq k \geq 0.25$ ) and $k<0.25$ conditions, $\sigma_{c c}$ will be reduced. When $k=0$, the strength envelope is the Mohr-Coulomb envelope.

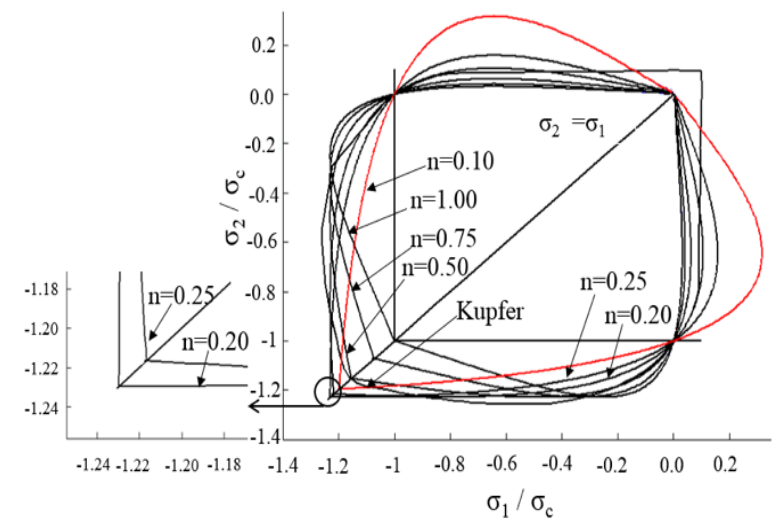

Fig. 2. The strength envelopes of different $k$ values

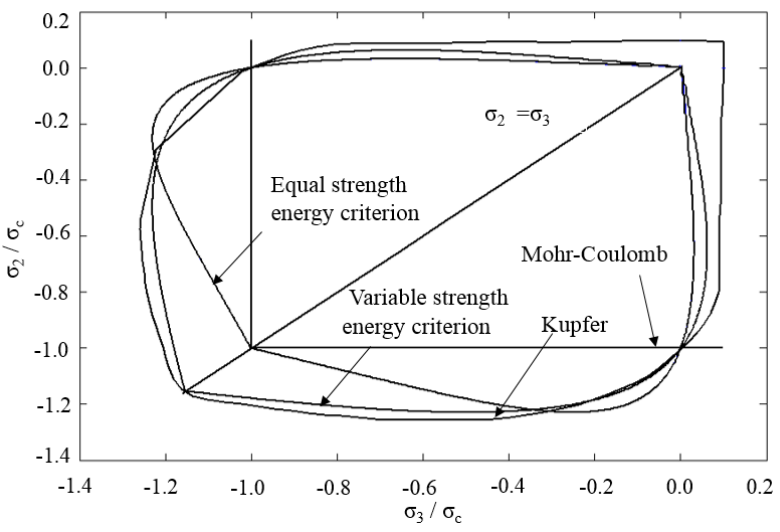

Fig. 3. The envelopes of different strength rules

3.1.2 Derivation of concrete variable-strength energy criterion on offset plane

Formula (17) is substituted into the Lode angle formula: 


$$
\begin{aligned}
& \tan \theta=\frac{1}{\sqrt{3}} \mu_{\sigma}=\frac{1}{\sqrt{3}}(2 \beta-1) \\
& =\frac{1}{\sqrt{3}} \frac{2 k \sigma_{2}-\sigma_{3}-\sigma_{1}}{\sigma_{1}-\sigma_{3}}
\end{aligned} .
$$

Formula (20) is substituted into Formula (4). Then, the concrete strength envelope according to the variable-strength energy criterion on the offset plane is obtained as shown in Fig. 4. When the frictional angle increases, the MohrCoulomb curve develops from an equilateral hexagon into an equilateral triangle.

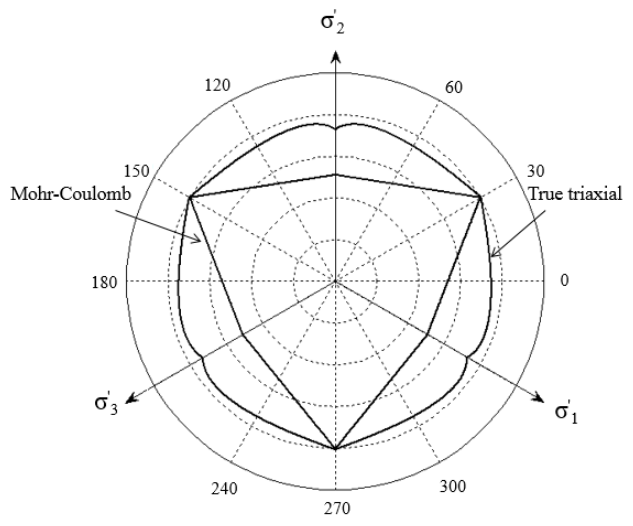

Fig. 4. The variable strength energy criterion curve of concrete on the deviatoric plane

\section{Results and analysis}

4.1 Numerical analog calculation models and parameters of compressive strength and shear strength of concrete specimen

Concrete is a kind of strain softening material. However, in the shear or compression-centered limit analysis, concrete can be regarded as an ideal plastic material. A numerical simulation of four different concrete specimens with different dimensions and shapes was performed based on the overload method and the finite difference software FLAC3D in the finite element limit analysis method.

Scheme I: The model was in accordance with the requirements specified in the Code for Design of Concrete Structures (GB50010-2010), and the simulated concrete specimens were cubes of $150-\mathrm{mm}$ sides. Constraints were imposed on the model undersurface, vertical downward uniformly distributed load was applied to top surface while transverse constraint was not applied, and the calculation model is shown in Fig. 5. However, to simulate the failure modes of the concrete specimens, a transverse friction constraint should be applied on the surface. The elasticplastic constitutive model and the Mohr-Coulomb criterion were used in the constitutive model, the specimens were considered ideal elastic-plastic materials, and the concrete models with four strength grades (i.e., C25, C30, C35, and C40) were calculated. Given no unified specifications and determination methods for concrete $c$ and $\varphi$ values, they were measured by combining the direct shear and uniaxial compression tests in this study, and the elasticity modulus and the Poisson's ratio were taken according to the Code for Design of Concrete Structures (GB50010-2010) as shown in Tab. 2. The similarity ratio of the test and calculation models was $1: 1$.

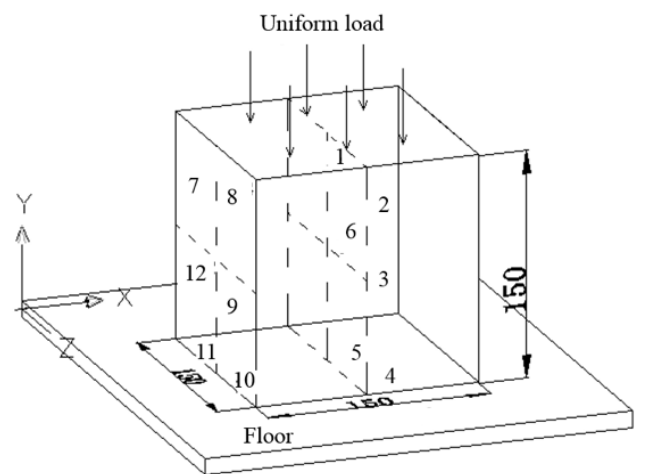

Fig. 5. Calculation model

Table 2. Parameters of concrete

\begin{tabular}{c|c|c|c|c|c}
\hline $\begin{array}{c}\text { Concrete } \\
\text { strength }\end{array}$ & $\begin{array}{c}\text { Elastic } \\
\text { modulus } \\
\text { / E/GPa }\end{array}$ & $\begin{array}{c}\text { Poisson's } \\
\text { ratio } / 1\end{array}$ & $\begin{array}{c}\text { Density/ } \\
\rho / \mathrm{kN}^{-3} \mathrm{~m}^{-3}\end{array}$ & $\begin{array}{c}\text { Cohesion/ } \\
\mathrm{c} / \mathrm{MPa}\end{array}$ & $\begin{array}{c}\text { Friction } \\
\text { angle } / \varphi{ }^{\circ}\end{array}$ \\
\hline $\mathrm{C} 25$ & 28.0 & 0.2 & 2400 & 3.2 & 61.3 \\
$\mathrm{C} 30$ & 30.0 & 0.2 & 2400 & 3.9 & 61.8 \\
$\mathrm{C} 35$ & 31.5 & 0.2 & 2400 & 4.5 & 62.2 \\
$\mathrm{C} 40$ & 32.5 & 0.2 & 2400 & 5.1 & 62.5 \\
\hline
\end{tabular}

4.2 Comparative analysis of measured result and numerical calculation result

The applied load was continuously adjusted in the calculation process, the load value when the model reached the ultimate failure mode was determined as the calculated value of the concrete compressive strength, and whether or not the model underwent failure was judged according to three criteria of geotechnical failure. The displacements in direction $Y$ of $1 \#$ point, directions $X$ and $Y$ of $8 \#$ point, directions $X$ and $Y$ of $9 \#$ point, and direction $X$ of 12\# point in Fig. 5 were monitored during the calculation. Fig. 6 displays the displacement time history curve in the convergence state of calculation, and the tail end of this curve shows a horizontal line, indicating that the displacement would no longer change and the calculation reached convergence. Fig. 7 presents the displacement time history curve in the non-convergence state, indicating that the displacement experienced a sudden change when the number of iterations reached 2,000, presenting an increasing tendency. In addition, the calculation did not reach convergence, indicating that the $\mathrm{C} 25$ concrete specimen already experienced failure.

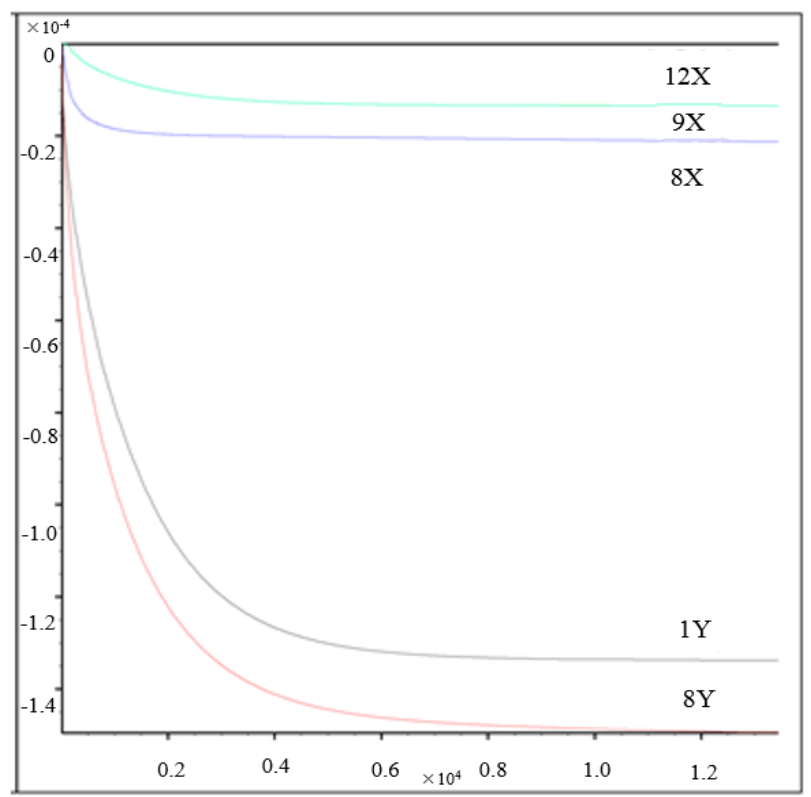

Fig. 6. Curves of key points disp when converged 
Liu Jun, Xiang Yuzhou, Xiong Yucheng, Wu zusong and He Chuan/

Journal of Engineering Science and Technology Review 13 (5) (2020)161 - 168

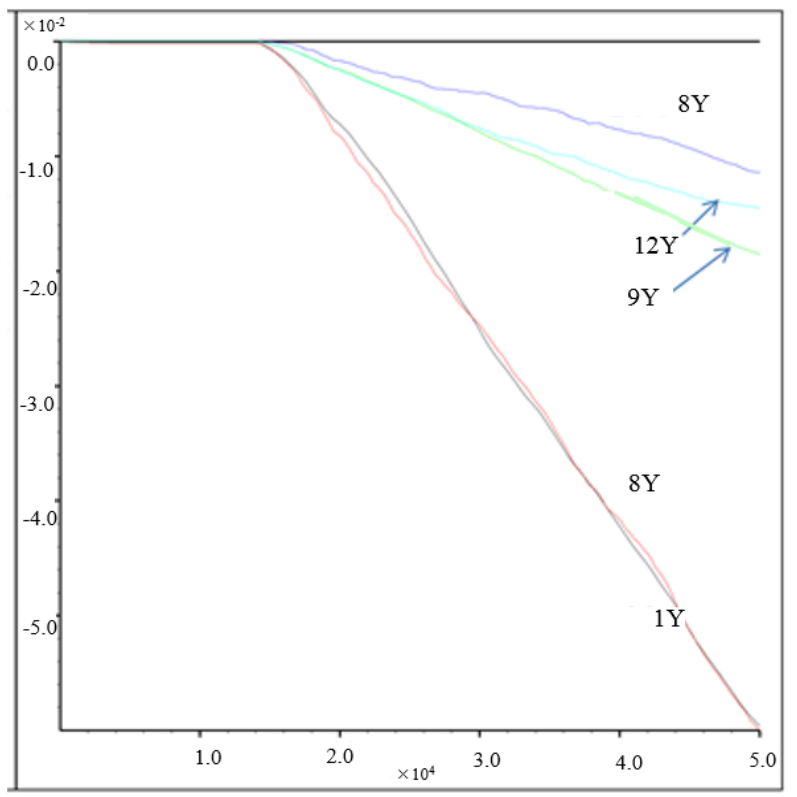

Fig. 7. Curves of key points disp when unconverged

Scheme I The theoretical test value and the calculated result of compressive strength were compared as shown in Tab. 3.

Scheme II The specimen was a cube with dimensions of $1500 \mathrm{~mm} \times 1500 \mathrm{~mm} \times 1500 \mathrm{~mm}$, while the other conditions were the same as those in Scheme I. The calculation results are listed in Tab. 4.

Scheme III The specimen was a cylinder with a diameter of $150 \mathrm{~mm}$ and a height of $300 \mathrm{~mm}$. The other conditions were the same as those in Scheme I. The calculation results are shown in Tab. 5.

Scheme IV The specimen was a cylinder with a diameter of $150 \mathrm{~mm}$ and a height of $150 \mathrm{~mm}$. The other conditions were the same as those in Scheme I. The calculation results are presented in Tab. 6 .

Table 3. The comparison of compressive strength measured values and the calculated results in SchemeI

\begin{tabular}{c|c|c|c}
\hline $\begin{array}{c}\text { Concrete } \\
\text { strength }\end{array}$ & $\begin{array}{c}\text { Calculation } \\
\text { value of } \\
\text { compressiv } \\
\text { e strength } \\
\text { /MPa }\end{array}$ & $\begin{array}{c}\text { Theoretical } \\
\text { test value of } \\
\text { compressive } \\
\text { strength } \\
\text { /MPa }\end{array}$ & $\begin{array}{c}\text { Error } \\
\text { between } \\
\text { calculated } \\
\text { value and } \\
\text { theoretical } \\
\text { value / } \%\end{array}$ \\
\hline C25 & 25.01 & 25.00 & 0.04 \\
C30 & 31.05 & 30.00 & 3.50 \\
C35 & 36.36 & 35.00 & 3.89 \\
C40 & 41.68 & 40.00 & 4.20 \\
\hline
\end{tabular}

Table 4. The comparison of compressive strength measured values and the calculated results in Scheme II

\begin{tabular}{c|c|c|c}
\hline $\begin{array}{c}\text { Concrete } \\
\text { strength }\end{array}$ & $\begin{array}{c}\text { Calculation } \\
\text { value of } \\
\text { compressive } \\
\text { strength } \\
\text { /MPa }\end{array}$ & $\begin{array}{c}\text { Theoretical } \\
\text { test value of } \\
\text { compressive } \\
\text { strength /MPa }\end{array}$ & $\begin{array}{c}\text { Error between } \\
\text { calculated value } \\
\text { and theoretical } \\
\text { value } / \%\end{array}$ \\
\hline C25 & 24.98 & 25.00 & 0.08 \\
C30 & 31.02 & 30.00 & 3.40 \\
C35 & 36.33 & 35.00 & 3.80 \\
C40 & 41.66 & 40.00 & 4.15 \\
\hline
\end{tabular}

Table 5. The comparison of compressive strength measured values and the calculated results in Scheme III

\begin{tabular}{c|c|c|c}
\hline $\begin{array}{c}\text { Concrete } \\
\text { strength }\end{array}$ & $\begin{array}{c}\text { Calculation } \\
\text { value of } \\
\text { compressive } \\
\text { strength } \\
\text { /MPa }\end{array}$ & $\begin{array}{c}\text { Theoretical } \\
\text { test value of } \\
\text { compressive } \\
\text { strength /MPa }\end{array}$ & $\begin{array}{c}\text { Error between } \\
\text { calculated value } \\
\text { and theoretical } \\
\text { value } / \%\end{array}$ \\
\hline C25 & 25.01 & 25.00 & 0.04 \\
\hline C30 & 31.05 & 30.00 & 3.50 \\
\hline C35 & 36.36 & 35.00 & 3.89 \\
\hline C40 & 41.68 & 40.00 & 4.20 \\
\hline
\end{tabular}

Table 6. The comparison of compressive strength measured values and the calculated results in Scheme IV

\begin{tabular}{c|c|c|c}
\hline $\begin{array}{c}\text { Concrete } \\
\text { strength }\end{array}$ & $\begin{array}{c}\text { Calculation } \\
\text { value of } \\
\text { compressive } \\
\text { strength } \\
\text { /MPa }\end{array}$ & $\begin{array}{c}\text { Theoretical } \\
\text { test value of } \\
\text { compressive } \\
\text { strength /MPa }\end{array}$ & $\begin{array}{c}\text { Error between } \\
\text { calculated value } \\
\text { and theoretical } \\
\text { value } / \%\end{array}$ \\
\hline C25 & 25.01 & 25.00 & 0.04 \\
C30 & 31.05 & 30.00 & 3.50 \\
C35 & 36.36 & 35.00 & 3.88 \\
C40 & 41.67 & 40.00 & 4.17 \\
\hline
\end{tabular}

Through the calculation of the four schemes, Tabs. 3, 4, 5 , and 6 indicate that the calculated compressive strength was very approximate to the theoretical test value, where the maximum and minimum errors were $4.20 \%$ and $0.04 \%$, respectively, and the error between the calculated compressive strength and the theoretical test value in different schemes under the same strength grade was very small, indicating that the concrete strength parameters $(c$ and $\varphi$ ) determined through the test were reasonable. Notably, the compressive strength was unrelated to the material dimensions or shape because concrete is regarded as ideal homogeneous material in the calculation, but the actual specimen was not a homogeneous material with a certain size effect.

4.3 Verification analysis of concrete shear strength through theoretical calculation and numerical calculation

According to the above study, $c$ could be obtained through the direct shear test ( $\varphi$ value could be solved through Formula (14)). Given the concrete compressive and shear strengths, the above numerical analysis and the theoretical formulas could be used to verify the accuracy of the shear strengths (Tab. 7). Tab. 8 lists the weights of the cohesion and frictional force in the compressive strength calculated through numerical analysis and the theoretical formula. Frictional force accounted for $47 \%$ of the shear strength, while the cohesion part accounted for $53 \%$. Meanwhile, Formula (14) could also prove the accuracy of the results shown in Tab. 8. Hence, frictional strength indeed exists in the concrete compressive strength, manifesting the correctness of the theoretical analysis.

Table 7. The verification of shear strength of different strength concrete

\begin{tabular}{|c|c|c|c|c|c|}
\hline \multirow[b]{2}{*}{$\begin{array}{l}\text { Concrete } \\
\text { strength }\end{array}$} & \multirow[b]{2}{*}{$\begin{array}{c}c \\
/ \\
\mathrm{Mpa}\end{array}$} & \multirow[b]{2}{*}{$\begin{array}{l}\varphi \\
{ }^{\mathrm{o}}\end{array}$} & \multicolumn{2}{|c|}{ Ultimate load } & \multirow{2}{*}{$\begin{array}{c}\text { Error } \\
\text { between } \\
\text { theoretical } \\
\text { solution and } \\
\text { numerical } \\
\text { solution } / \%\end{array}$} \\
\hline & & & $\begin{array}{c}\text { Theoretical } \\
\text { solution/ } \\
\sigma_{1}\end{array}$ & $\begin{array}{c}\text { Numerical } \\
\text { solution/ } \\
\sigma_{1}\end{array}$ & \\
\hline $\mathrm{C} 20$ & 2.6 & 60.09 & 20.03 & 20.03 & 0.0000 \\
\hline
\end{tabular}


Liu Jun, Xiang Yuzhou, Xiong Yucheng, Wu zusong and He Chuan/ Journal of Engineering Science and Technology Review 13 (5) (2020)161 - 168

\begin{tabular}{l|l|l|l|l|l}
$\mathrm{C} 25$ & 3.2 & 61.3 & 25.02 & 25.01 & 0.0278 \\
$\mathrm{C} 30$ & 3.9 & 61.8 & 31.05 & 31.05 & 0.0100 \\
$\mathrm{C} 35$ & 4.5 & 62.2 & 36.37 & 36.36 & 0.0201 \\
$\mathrm{C} 40$ & 5.1 & 62.5 & 41.68 & 41.68 & 0.0095 \\
$\mathrm{C} 45$ & 5.6 & 62.7 & 46.12 & 46.13 & 0.0236
\end{tabular}

\begin{tabular}{l|l|l|l} 
C50 & 6.1 & 62.9 & 50.6 \\
C55 & 6.6 & 63.1 & 55.19 \\
C60 & 7.2 & 63.3 & 60.68 \\
\hline
\end{tabular}

\begin{tabular}{l|l|l}
50.62 & 50.61 & 0.0237 \\
55.19 & 55.19 & 0.0074 \\
60.68 & 60.67 & 0.0160 \\
\hline
\end{tabular}

Table 8. Value of shear strength of concrete

\begin{tabular}{|c|c|c|c|c|c|c|c|c|c|c|}
\hline \multirow{2}{*}{$\begin{array}{c}\text { Concrete } \\
\text { strength }\end{array}$} & \multicolumn{2}{|c|}{$\begin{array}{c}\text { Compressive strength } \\
/ \sigma_{1}\end{array}$} & \multicolumn{2}{|c|}{ Shear strength / $\tau$} & \multicolumn{3}{|c|}{ Cohesion $/ c$} & \multicolumn{3}{|c|}{ Friction $/ \sigma \tan \varphi$} \\
\hline & Theory & $\begin{array}{l}\text { Numerical } \\
\text { simulation }\end{array}$ & Theory & $\begin{array}{l}\text { Numerical } \\
\text { simulation }\end{array}$ & Theory & $\begin{array}{l}\text { Numerical } \\
\text { simulation }\end{array}$ & Weight & Theory & $\begin{array}{l}\text { Numerical } \\
\text { simulation }\end{array}$ & Weight \\
\hline $\mathrm{C} 20$ & 20.03 & 20.03 & 4.87 & 4.87 & 2.60 & 2.60 & 0.53 & 2.27 & 2.27 & 0.47 \\
\hline $\mathrm{C} 25$ & 25.02 & 25.01 & 6.01 & 6.01 & 3.20 & 3.20 & 0.53 & 2.81 & 2.81 & 0.47 \\
\hline $\mathrm{C} 30$ & 31.05 & 31.05 & 7.34 & 7.34 & 3.90 & 3.90 & 0.53 & 3.44 & 3.44 & 0.47 \\
\hline $\mathrm{C} 35$ & 36.37 & 36.36 & 8.48 & 8.48 & 4.50 & 4.50 & 0.53 & 3.98 & 3.98 & 0.47 \\
\hline $\mathrm{C} 40$ & 41.68 & 41.68 & 9.62 & 9.62 & 5.10 & 5.10 & 0.53 & 4.52 & 4.52 & 0.47 \\
\hline $\mathrm{C} 45$ & 46.12 & 46.13 & 10.58 & 10.58 & 5.60 & 5.60 & 0.53 & 4.98 & 4.98 & 0.47 \\
\hline C50 & 50.62 & 50.61 & 11.53 & 11.53 & 6.10 & 6.10 & 0.53 & 5.43 & 5.43 & 0.47 \\
\hline C55 & 55.19 & 55.19 & 12.48 & 12.48 & 6.60 & 6.60 & 0.53 & 5.89 & 5.89 & 0.47 \\
\hline C60 & 60.68 & 60.67 & 13.63 & 13.63 & 7.20 & 7.20 & 0.53 & 6.43 & 6.43 & 0.47 \\
\hline
\end{tabular}

(3) Given the concrete compressive strength, the

\section{Conclusions}

To further study the shear strength characteristics of concrete materials, the theoretical relationships among concrete shear stress, normal stress, and shear strength were analyzed through theoretical derivation. Meanwhile, the theoretically calculated concrete shear strength was numerically verified via numerical simulation. The following conclusions could be drawn:

(1) The concrete compressive strength shows a certain theoretical relationship with shear strength, and theoretical formulas of the concrete materials under the triaxial and biaxial stress states were derived and analyzed. The theoretical formula in the triaxial stress state is only applicable in cases consistent with the 3D Mohr's circle theory with equal compressive strengths in the biaxial and uniaxial stress states, which is called constant-strength energy strength criterion.

(2) The analysis indicates that the 3D Mohr's circle theory cannot be fully adopted to study concrete material, especially when the compressive strength in the biaxial stress state is larger than that in the uniaxial stress state. Therefore, the constant strength energy criterion should be corrected in terms of concrete shear strength. accuracy of the shear strengths of concrete materials with different strength grades is verified based on theoretical calculation and numerical analysis. The numerical simulation shows that concrete material gains its shear strength 47 percent from its frictional force while the rest form cohesive force.

The concrete shear strength was investigated in this study through theoretical derivation and numerical simulation. The theoretical relationship between concrete compressive and shear strengths was established, thus providing a new idea for future studies regarding concrete shear strength. However, restricted by the length of the study, no laboratory test was implemented for verification. The author will continue relevant experimental studies to derive more useful mechanical characteristic laws of concrete shear strength and enrich the research results.

\section{Acknowledgements}

The authors are grateful for the support provided by the National Natural Science Foundation of China (Grant No. 51808083).

This is an Open Access article distributed under the terms of the Creative Commons Attribution License

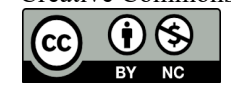

\section{References}

1. Qassim, A. A., "Behavior of normal, high and ultra-high strength concrete in direct shear". International Journal of Civil Engineering and Technology, 92(9), 2018, pp.349-360.

2. Ali, M. A., White, R. N., "Enhanced contact model for shear friction of normal and high-strength concrete". American Concrete Institute Structural Journal, 96(3), 1999, pp.348-360.

3. Chi, Y., Xu, L. H., Mei, G. D., Hu, N., Su, J., "A unified failure envelope for hybrid fibre reinforced concrete subjected to true triaxial compression". Composite Structures, 109, 2014, pp.31-40.

4. Waseem, S. A., Singh, B., "Shear transfer strength of normal and high-strength recycled aggregate concrete - An experimental investigation". Construction and Building Materials, 125, 2016, pp.29-40.

5. Waseem, S. A., Singh, B., "Shear transfer in normal-and highstrength recycled aggregate concrete". Journal of testing and evaluation, 46(1), 2018, pp. 178-190.

6. Wang, H. L., Tian, P., "Strength and Deformation Characteristics of RCC Under Dynamic Compressive-shear Loading". Journal of Water Resources and Architectural Engineering, 14(2), 2016, pp.21-27.
7. Bui, T. T., Nana, W. S. A., Abouri, S., "Influence of uniaxial tension and compression on shear strength of concrete slabs without shear reinforcement under concentrated loads". Construction and Building Materials, 146, 2017, pp.86-101.

8. Wong, R. C. K., Ma, S. K. Y., Wong, R. H. C., "Shear strength components of concrete under direct shearing". Cement and Concrete Research, 37(8), 2007, pp.1248-1256.

9. Liu, B., Feng, C., Deng, Z., "Shear behavior of three types of recycled aggregate concrete". Construction and Building Materials, 217, 2019, pp.557-572.

10. Yu Z., Huang Q., Xie X., Xiao, N., "Experimental study and failure criterion analysis of plain concrete under combined compressionshear stress". Construction and Building Materials, 179, 2018, pp.198-206.

11. French, R., Maher, E., Smith, M., "Direct shear behavior in concrete materials". International Journal of Impact Engineering, 108, 2017, pp.89-100.

12. Cong, Y., Kong, L., Zheng, Y. R., "Experimental study on shear strength of concrete". Concrete, 307(5), 2015, pp.46-51. 
Liu Jun, Xiang Yuzhou, Xiong Yucheng, Wu zusong and He Chuan/

\section{Journal of Engineering Science and Technology Review 13 (5) (2020)161 - 168}

13. Rukhaiyar, S., Sajwan, G., Samadhiya, N. K., "Strength behavior of plain cement concrete subjected to true triaxial compression". Canadian Journal of Civil Engineering, 45(3), 2018, pp.179-196.

14. Javanmardi, P., "Experimental Study of Triaxial Behavior of Concrete under Lateral Confining Stress". Open Civil Engineering Journal, 11(1), 2017, pp.281-291.

15. Yang, H., Qin, Y., Liao, Y., "Shear behavior of recycled aggregate concrete after exposure to high temperatures". Construction and Building Materials, 106, 2016, pp.374-381.

16. Ahmed L., Ansell, A., "Direct shear strength of high-strength fibre concrete". Magazine of Concrete Research, 62(5), 2010, pp.379390 .

17. Wang, Z. L., Yang, D., Wu, L. P., "Experimental research on compression-shear failure of ultrashort steel fiber reinforced concrete". Concrete, 253(11), 2010, pp.101-103.
18. Deng, Z. H., Liao, Y., Meng, C. L., "Experimental Study on the Shearing Property of Equal Strength Recycled Coarse Aggregate Concrete". Applied Mechanics and Materials, 357-360(8), 2013, pp.1420-1427.

19. Arezoumandi, M., Volz, J. S., Ortega, C. A., "Shear behavior of high-volume fly ash concrete versus conventional concrete: Experimental study". Journal of Structural Engineering, 141(3) 2015, pp. 1506-1513.

20. Lim, J. C., Ozbakkaloglu, T., Gholampour, A., Bennett, T., "Finiteelement modeling of actively confined normal-strength and highstrength concrete under uniaxial, biaxial, and triaxial compression". Journal of Structural Engineering, 142(11), 2016, pp.1-12. 